\title{
6 QTL analysis in Barley Across Environments in Egypt
}

\author{
M. A. Sayed, A.N. El-sadek*\#, B, A. Bakry**, M. B. Ali , Jens Leon*** and E. M. \\ Salem* \\ Agronomy Department, Faculty of Agriculture, Assiut University, Assiut 71526; \\ "Ecology \& Dry Land Agriculture Division, Desert Research Center, El- \\ Matarya; ${ }^{* *}$ Field Crops Department, National Research Centre, Cairo, Egypt and \\ *** Plant Breeding, INRES, Faculty of Agriculture, Bonn University, Germany
}

Received: $6 / 1 / 2017$ Accepted: $5 / 4 / 2017$
$\mathrm{B}$ ARLEY is one of the most important cereal crops worldwide. An advanced backcross doubled haploid mapping population was grown in four locations across Egypt (Assuit, Al Wady Al Asuity, Matrouh and Nubaria). The population included $301 \mathrm{BC} 2 \mathrm{DH}$ lines derived from crossing between a German elite cultivar of H. vulgare ssp. vulgare 'Scarlett' with an exotic accession of H. vulgare ssp. spontaneum 'ISR42-8'. A linkage map including 371 different types of genetic markers was used to perform QTL analysis. We detected 56 putative QTLs for traits of interest. In addition, the study identified four markers with marker main and marker $\times$ environment interaction effects. The exotic alleles of those four markers could be responsible for increasing their traits across environments. Furthermore, eight markers showed pleiotropic effect across locations. Some DH lines performed better than their parents and check varieties in each environment and across four environments as well. These results might be useful in MAS for barley breeding programs in Egypt.

Keywords: Barley, Epistatic effects, Multiple environments, Pleiotropic effects, Quantitative trait loci.

\section{INTRODUCTION}

Barley (Hordeum vulgare L.) is an important cereal crop that comes next after wheat, maize and rice based on the production and the harvested area (FAOSTAT 2014). It is adapted to hot and dry climate, salinity, low soil fertility, however moderately cool and dry climate is suited for the crop production (Mishra \& Shivakumar , 2000). The crop is cultivated in a wide range of environments including North Africa, the near and Middle East, South Asia, Russia, Eastern Asia, Europe, Australia and South America. In Egypt, almost $93 \%$ of the cultivated area of barley is mainly under rainfed condition in the North Western Coastal Zone (NWCZ) covering an area of 126,000 ha with an average productivity of $1.29 \mathrm{t} \mathrm{ha}^{-1}$ (Noaman, 2010) as of 2008/2009 season.

Barley variety development in Egypt is concentrated in developing drought-tolerant and high yielding-cultivars to satisfy the environmental needs in the marginal areas (under low rainfall and prolonged salinity and heat stress conditions). Because of these efforts for highly drought-tolerant, high-yielding barley cultivars have been recently released, namely Giza 125 (Noaman et al. 1995a and b), Giza126 (Noaman et al. 1995c), Giza 2000 (Noaman et al. 2007a) and Giza 132 (Noaman et al. 2007b). Moreover, great efforts have been made to release new barley cultivars for special purposes, for example; two two-row barley cultivars for the malting and brewery industries i.e., Giza 127 and Giza 128 (El-Sayed et al., 1995) and three hull-less barley cultivars for human feed were released namely Giza 129, Giza 130 and Giza 131 (El-Sayed et al., 2003).

The differential response of a genotype across environments is defined as the genotype $(\mathrm{G}) \times$ environment (E) interaction (GEI) (Beyene et al. 2011 and Kang, 2004). The GEI is a crucial objective in the breeding programs; first, it helps 
to identify the adapted genotype for each location instead of using the genotypes mean over all the studied locations or environments in the selection process (Adugna, 2007). Secondly, it examines the adaptability of subdividing the target region to mega-environments (Yan et al., 2000)

Seed yields of all crops including barley depends mainly on the yield components, which are controlled by several genes, and the effects of these genes are modified by environmental factors. (Singh et al., 1993 and Hayes et al. 1993). With the advancement in the molecular markers and mapping techniques, the locations of the genes which influence the agronomic traits related to the yield can be detected, and these locations are called quantitative trait loci (QTLs) which is vitally important for marker-assisted selection for yield improvement ( $\mathrm{Li}$ et al. 2011). When these QTLs have different expressions across the tested environments, this called the QTL by environment interaction (QEI).

QTL analysis has been intensively utilized for all crops including barley. Since the first barley genetic map was constructed from RFLP marker, many genetic maps were created using various genetic markers, including the use of one type of markers i.e. RFLP (Kandemir et al. 2000) SSR (Li et al., 2006) to map quantitative trait loci (QTLs) in an advanced backcross population of barley, DArT marker (Tondelli et al., 2014) to study the QTLs responsible for barley yield adaptation to the Mediterranean environments. Some studies used two type of markers i.e., RFLP and SSR (Wang, et al. 2014), SNP and SSR markers (Wang et al., 2016) to identify QTLs and QTL $\times$ environment interactions for ten grain yield-related traits in a late-generation double haploid population $(\mathrm{DH})$ derived from the Huaai $11 \times$ Huadamai 6 cross . Cuesta-Marcos et al. (2008) used 215 markers: 10 RFLP, 5 STS, 515 RAPD, 112 AFLP and 73 SSR (15 ESTs and 58 genomic-derived markers, to discover grain yield QTL in a doubled haploid 25 population of barley that is highly productive under the inland plains of Spain. These maps were utilized to identify the QTLs for various economic traits.

Epistasis states to the phenotypic effects of interactions among alleles at multiple loci. It is defined as the deviation from additivity of the effects between alleles of different loci (Cockerham, 1954). With the expanding use of molecular markers in plant species, it has been revealed that epistatic effects play a crucial role on understanding the genetic basis of quantitative traits (Lark et al., 1995; Maughan et al. 1996; Li et al., 1997 and $\mathrm{Yu}$ et al., 1997). The objective of the current study was to identify QTLs controlling important characters such as yield and yield components of barley grown in different environments in Egypt.

\section{MATERIALS AND METHODS}

\section{Plant material}

An advanced backcross doubled haploid mapping population consisted of $301 \mathrm{BC} 2 \mathrm{DH}$ lines (DH) derived from crossing between a German elite cultivar of $H$. vulgare ssp. vulgare 'Scarlett' with an exotic accession of $H$. vulgare ssp. spontaneum 'ISR42-8'. The population was designated as S42 and used for QTL analysis across environments in current study. The cultivar Scarlett was used as the recurrent parent whereas ISR42-8 was utilized as the donor. More details about development of this population and proportion of donor genome are given in von Korff et al. (2004) and Schmalenbach et al. (2008). For comparison with barley local cultivars, four commercial cultivars of barley, i.e. Giza 123, Giza 127, Giza 129 and Giza 2000 were used in this study as check cultivars.

\section{Experimental sites and design}

These experiments were conducted in the 2013/2014 and 2014/2015 growing seasons at four different locations in Egypt (Fig. 1) namely, Assiut (AS), Wadi El-Assiuty farm (WAD) Nubaria farm (NU) Matrouh farm (MA ).

The four locations names, latitudes, longitudes, soil type and irrigation system are presented in Table 1. The experiments were arranged in a randomized complete block design (RCBD) with two replications. The genotypes were randomly grown in plots; each plot consisted of one row 6 $\mathrm{m}$ long and $0.20 \mathrm{~m}$ apart .

\section{Cultural practices}

Plants were irrigated using surface irrigation system, while sprinkle irrigation system was used to irrigate plants in the other environments. Total irrigation requirements in these areas were applied as recommended for such these locations. In case of having rains, we omitted the amount of water gained by rains from the total irrigation requirements. The recommended doses of NPK fertilizers were added and normal cultural practices of growing winter cereals conducted in the usual manner followed by the farmers of this district. Phenotypic data 


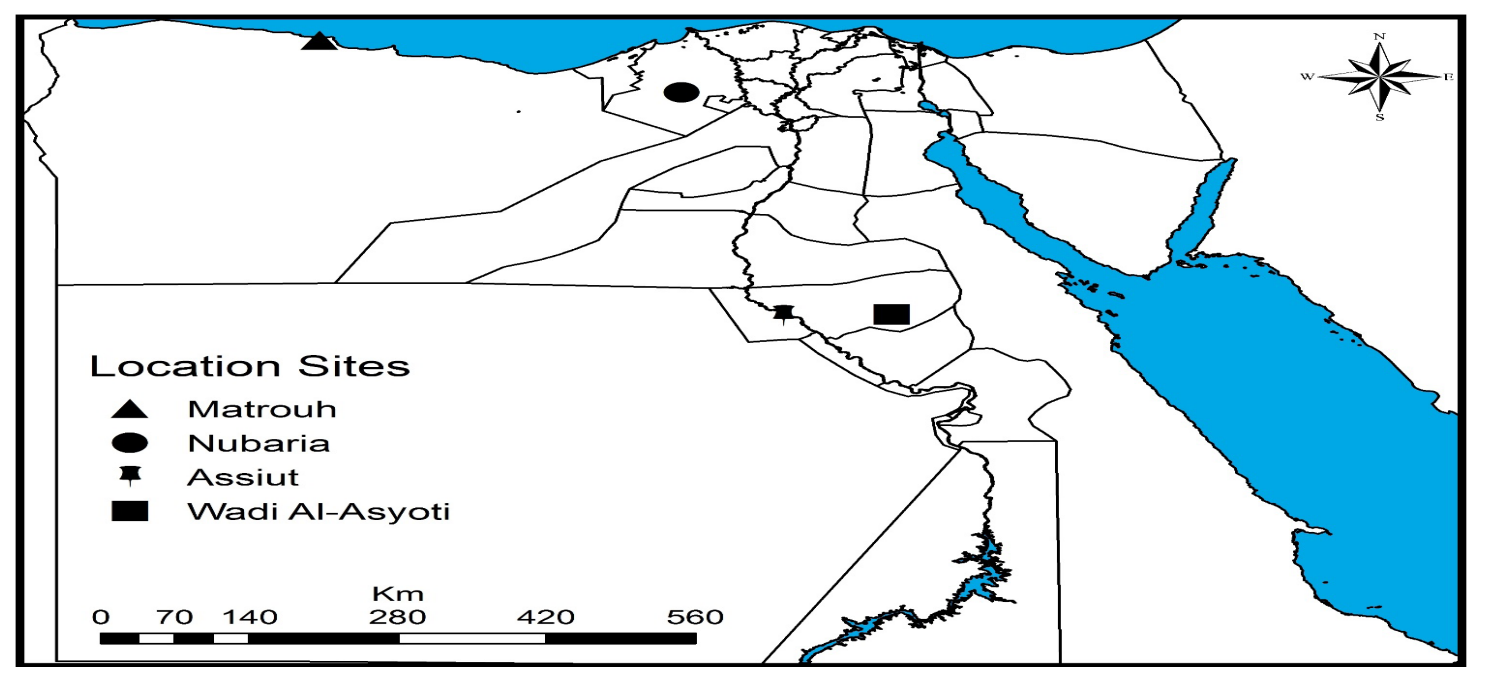

Fig. 1. Map of Egypt showing the four locations.

TABLE 1. Latitude, longitude, soil type and rain status of the four investigated environments.

\begin{tabular}{|l|c|c|c|c|}
\hline Location & $\begin{array}{c}\text { Assiut Farm } \\
\text { (AS) }\end{array}$ & $\begin{array}{c}\text { Al-Wady Al-Asyoti } \\
\text { (WAD) }\end{array}$ & Nubaria (NU) & Matrouh (MA) \\
\hline Growing season & $2013 / 2014$ & $2013 / 2014$ & $2013 / 2014$ & $2014 / 2015$ \\
Latitude & $27^{\circ} 11^{\prime} 1.13^{\prime \prime}$ & $27^{\circ} 12^{\prime} 20.83^{\prime \prime}$ & $30^{\circ} 32^{\prime} 14.733^{\prime}$ & $31^{\circ} 21^{\prime} 12^{\prime}$, \\
Longitude & $31^{\circ} 9^{\prime} 49.49^{\prime \prime}$ & $32^{\circ} 4^{\prime} 28.51^{\prime \prime}$ & $30^{\circ} 17^{\prime} 56.11^{\prime \prime}$ & $27^{\circ} 11^{\prime} 14^{\prime}$, \\
Type of soil & Clay & Sandy Loam & Sandy Loam & Sandy clay loam \\
Rains status & rare & rare & & $81.60 \mathrm{~mm}$ \\
Irrigation system & surface & Sprinkle & Sprinkle & Sprinkle \\
\hline
\end{tabular}

Heading date (HD) for each genotype was recorded as the number of days from the sowing date until $50 \%$ of tillers had emergence a half of spikes from the flag leaf sheath (Zadok et al., 1974). At anthesis time, chlorophyll content (CC) of the flag leaf was measured using a selfcalibrating SPAD chlorophyll meter (Model 502, Spectrum Technologies, Plainfield, IL) from 10 randomly flag leaves, then the average was scored. This measurement directly estimated the chlorophyll content of the flag leaf (Xu et al., 2000). At maturity time, 10 individual plants were randomly chosen in the middle for each row to measure plant height $(\mathrm{PH} ; \mathrm{cm})$. At harvest, 8-12 guarded individual plants were randomly harvested to measure the yield traits: the average spikes number per plant (NSP), 100-grain weight (100-GW; g) and the average grain yield per plant (GYP;g).

\section{Genotyping of population S42}

The S42 population was genotyped with a total number of 371 genetic markers containing 106 SSRs according to von Korff et al. (2004), 255 DArT following (Sayed et al., 2012) and ten gene-specific DNA markers referred to Wang et al. (2010) in order to perform QTL analysis. The linkage map of this population was drawn using MapChart ver.2.2 (Voorrips, 2002).

\section{Statistical and QTL analysis \\ Analysis of variance}

To detect the differences among tested genotypes, among environments and the $\mathrm{G} \times \mathrm{E}$ interaction, the combined analysis of variance was performed with the Statistical Analysis System SAS (SAS Institute, ver. 9.2 2008), using PROC GLM procedure. The phenotypic correlations among trait performances were computed using the correlation procedure (PROC CORR). The LS-means of the investigated traits across the DH 
lines over replication were used for the calculation of the Pearson correlation coefficients (r).

\section{Broad-sense heritability estimation}

Broad-sense heritability ( $\left.h^{2} \mathrm{~B}\right)$ was computed as $h^{2} B=\delta^{2} \mathrm{G} /\left(\delta_{\mathrm{G}^{2}}+\delta^{2}{ }_{\mathrm{G} \times \mathrm{E}} / \mathrm{e}+\delta^{2}\right.$ /er), where $\delta^{2}{ }_{\mathrm{G}}, \delta_{\mathrm{G} \times \mathrm{E}}^{2}$ and $\delta^{2}$ e were the estimates of genetic, genotype $\times$ environments interaction and error variances, respectively, derived from the expected mean squares of the combined analysis of variance. Also e and $r$ were the number of environments (locations) and replications, respectively. $R P$

Relative performance of the exotic parent The relative performance of the exotic parent $\mathrm{RP}_{[\mathrm{Hsp}]}$ was computed by this formula:

$$
R P_{[H s p]}=(([H s p]-[H v]) /[H v]) * 100,
$$

where [Hsp] represents LS-means of the homozygous exotic genotype and $[\mathrm{Hv}]$ represents LS-means of the elite genotype.

\section{QTL analysis}

The QTL analysis was conducted using a multiple QTL model iteratively extended and reduced by forward selection and backward elimination, respectively using the PROC MIXED procedure in SAS software as per (Sayed et al., 2012). Starting point was the following mixed hierarchical model:

$$
X_{i j k l}=\mu+M i+L_{j}\left(M_{i}\right)+E_{k}+L_{j}^{*} E_{k}+M_{i} E_{k}+\varepsilon l(i j k),
$$

where the total of phenotypic value was sum of general mean $\mu$, fixed effect $\mathrm{Mi}$ of the i-th marker genotype, random effect $\mathrm{Lj}(\mathrm{Mi})$ of the $\mathrm{j}$-th DH line nested in the i-th marker genotype, fixed effect $\mathrm{Ek}$ of the $\mathrm{k}$-th environment, fixed interaction effect $\mathrm{L}_{\mathrm{j}}{ }^{*} \mathrm{E}_{\mathrm{k}}$ of the $\mathrm{j}$-th $\mathrm{DH}$ line and the $\mathrm{k}$-th environment, fixed interaction effect Mi*Mk of the i-th marker genotype and the k-th environment and residue $\varepsilon_{(\mathrm{ijk})}$ of $\mathrm{X}_{\mathrm{ijkl} .} \mathrm{P}$ values from F-tests were adjusted genome-wide across all single marker tests using the false discovery rate (FDR). The significant marker main effects as well as marker $\times$ environments interaction with PFDR $\leq 0.05$ were accepted as putative QTLs for the next iteration, however, the final model was:

$$
\begin{aligned}
& X_{i j k l}=\mu+\sum Q T L+M i+L j(M i)+E_{k}+L j * E k+M i * E \\
& k+\varepsilon l(i j k),
\end{aligned}
$$

where $\sum$ QTL represents the detected QTL from the forward/backward selection process. The contribution of a QTL to trait genotypic variance was estimated by the $\mathrm{R}^{2}$ coefficient (percentage of the explained genotypic variance) according to von Korff et al. (2004).

\section{Digenic epistatic effects}

The digenic epistatic interactions between all DArT and SSR marker pairs were tested with SAS procedure MIXED (SAS ver. 9.2, SAS Institute 2008) using the following mixed hierarchical model:

$$
\begin{gathered}
X_{i j k l m}=\mu+\sum Q T L+M 1_{i}+M 2_{j}+M 1_{i} * M 2_{j}+L k\left(M_{l i} * M\right. \\
2 j)+E l+L j * T k++\varepsilon_{l(i j k m)}
\end{gathered}
$$

where $\mathrm{M} 1_{\mathrm{i}}$ and $\mathrm{M} 2_{\mathrm{j}}$ are the fixed effects of the $\mathrm{i}$-th marker and $\mathrm{j}$-th marker (M2). M1 $1 * \mathrm{M} 22_{\mathrm{j}}$ is the fixed interaction effect of the $\mathrm{i}$-th M1 genotype with $\mathrm{j}$-th M2 genotype, $\mathrm{Lk}\left(\mathrm{M} 1 \mathrm{i}^{*} \mathrm{M} 2 \mathrm{j}\right)$ is the random effect of the k-th BC2DH line nested in the $i$-th $\mathrm{M} 1$ and $j$-th M2 marker genotype interaction.

\section{RESULTS AND DISCUSSION}

\section{Analysis of variance}

Data in Table 2 shows the combined analysis of variance of the investigated traits across four environments. There were highly significant differences among environments, among the 307 genotypes (301 DH lines, their parents and four check cultivars) for all investigated traits Furthermore, the genotype $\times$ environment interaction was highly significant for all studied traits. This finding reflected the existence of sufficient variation among genotypes for investigated traits. The coefficient of variation ranged between $3.13 \%$ (heading date) and 25.68\% (number of spikes per plant). Across locations, grain yield per plant and seed index showed the lowest values of heritability in broad sense, while heading date showed the highest heritability value.

Data presented in Table 3 shows the mean, minimum, maximum and standard deviation (SD) values of Scarlett, ISR 42-8, S42 population, check cultivars and over all genotypes in each location and across environments. Wide ranges of all studied traits were observed for all genotypes at each environment and across environments as well. Across environments, Scarlett was earlier than ISR 42-8 in all investigated environments, by values ranged between 4 days (Nubaria and Matrouh) and 10 days (Assiut). Furthermore, Scarlett was shorter, less in chlorophyll content, less in number of spikes per plant, heaver in 100 -grain weight and produced more grains per 
plant than the wild accession ISR 42-8. The S42 population exhibited transgressive segregation in all studied traits in each environment and across environments as well, reflecting the sufficient variation among $\mathrm{DH}$ lines for selection. On average, DH lines were significantly earlier than ISR 42-8 and later than check cultivars in all environments .

Days to heading of DH lines ranged between 60.5 and 111 days, this means selection for earliness can be done among these lines in each environment. Scarlett and DH lines were shorter than check cultivars and ISR 42-8 across all environments. DH lines, their parents and check cultivars showed approximately stability values of chlorophyll content across the four locations (Table 3). For number of spikes per plant, DH lines showed a wide range of spikes per plant with an average of 8.28 spike across environments. On average, DH lines had higher seed index (3.81 g) than ISR 42-8 (1.82 g) and Scarlett $(3.73 \mathrm{~g})$ across environments. While the local check cultivars showed the maximum mean value of seed index (4.32 g) across environments. Some of the DH lines exceeded in seed index (maximum $6.7 \mathrm{~g}$ ) the average of check cultivars (4.32 g) and Scarlett (3.73 g), this may be indicating the ability of finding high genotypes in grains weight in each environment. The average of DH lines for grain yield/plant (GYP) was lower $(5.51 \mathrm{~g})$ than the best parent Scarlett $(5.95 \mathrm{~g})$ and check cultivars (5.56) but they have a wide range of GYP across environments. This wide range refers to the possibility for selection of superior genotypes of barley in each environment.

In addition, it can be observed that, the genotypes were earlier at Assiut and Wadi ElAssiuty environments than in Nubaria and Matrouh, this may be due to the effect of high temperature in Upper Egypt than in Delta and North of Egypt. While the plants were taller in Assiut and Wadi El-Assiuty than in Nubaria and Matrouh. Assiut was the best environment for plant growth and productivity of the current materials, since it produced the higher grain yield per plant and high seed index. This result may be due to the clay soil conditions that rich in nutrients and availability of irrigation, while the other environments, the soil is sand and rely on sprinkle irrigation system. Our results are consistent with Zhu et al (1999) who found significant variation among DH lines within each environment and there were both positive and negative transgressive segregates. Furthermore, Xue et al (2008) studied chlorophyll content in barley and found significant transgressive segregation among DH lines.

\section{Correlation among traits}

Mutual correlation coefficients among studied traits across the four environments are presented in Table 4. There was negative and significant correlation between days to $50 \%$ heading and each of plant height $(\mathrm{r}=-0.391 * *)$, chlorophyll content $\left(\mathrm{r}=-0.172^{* *}\right)$, seed index $\left(\mathrm{r}=-0.448^{* *}\right)$, while it was positive and highly significant with each of number of spikes per plant $(\mathrm{r}=0.384 * *)$ and grain yield per plant $\left(\mathrm{r}=0.225^{* *}\right)$ across all environments. Plant height

TABLE 2 . Mean squares, coefficient of determination, coefficient of variation and heritability in broad sense of six studied traits for 307 genotypes across four environments.

\begin{tabular}{|c|c|c|c|c|c|c|c|}
\hline \multirow{2}{*}{ Source } & \multirow{2}{*}{ d.f. } & \multicolumn{6}{|c|}{ Mean squares } \\
\hline & & HD & $\mathrm{PH}$ & $\mathrm{CC}$ & NSP & SI & GYP \\
\hline Environment (E) & 3 & $33834 * *$ & $204960 * *$ & $3238.52 * *$ & $6193.3 * *$ & $335.02 * *$ & $4046.15 * *$ \\
\hline $\mathrm{E}(\mathrm{Rep})$ & 4 & 55.35 & 92.45 & 41.05 & 70.91 & 3.21 & 31.60 \\
\hline Genotype (G) & 306 & $149.27 * *$ & $565.29 * *$ & $101.37 * *$ & $65.70 * *$ & $1.68 * *$ & $12.33^{* *}$ \\
\hline $\mathrm{G}^{*} \mathrm{E}$ & 918 & $41.76^{* *}$ & $248.89 * *$ & $35.72 * *$ & $20.18^{* *}$ & $0.67 * *$ & $14.07 * *$ \\
\hline Error & 1224 & 9.01 & 25.38 & 13.77 & 5.04 & 0.03 & 0.94 \\
\hline $\mathrm{R}^{2}$ & & 0.94 & 0.97 & 0.81 & 0.90 & 0.99 & 0.96 \\
\hline C.V. $\%$ & & 3.13 & 7.37 & 7.64 & 25.68 & 4.27 & 17.64 \\
\hline$h^{2}{ }_{B}$ & & 0.720 & 0.575 & 0.666 & 0.626 & 0.069 & 0.064 \\
\hline
\end{tabular}




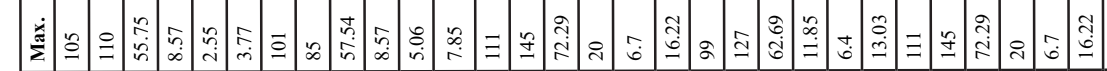

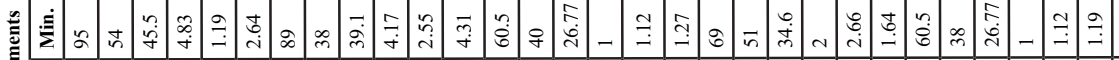 \\ 言

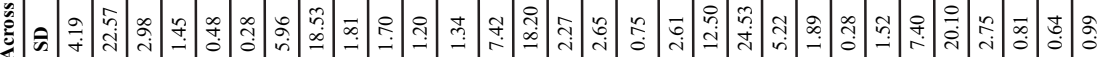

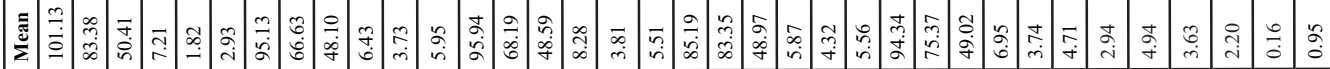

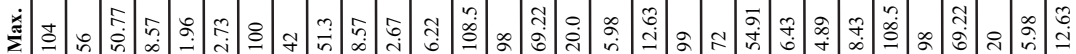

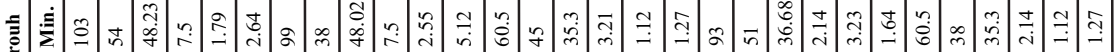

(3)

$\frac{5}{2}$

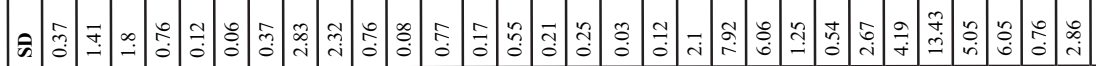

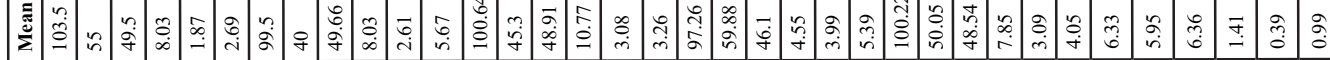

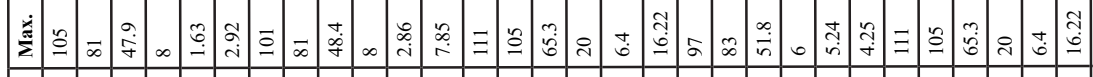

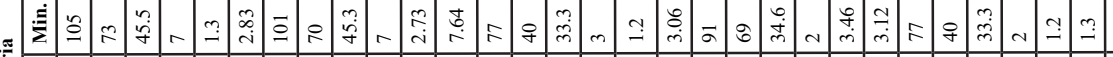

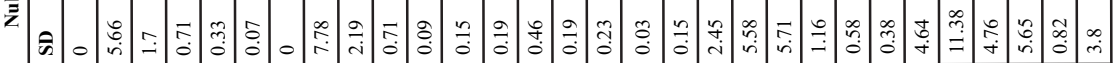

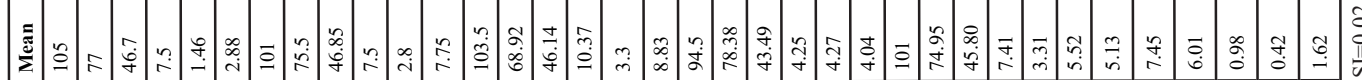

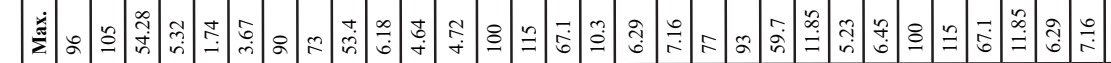

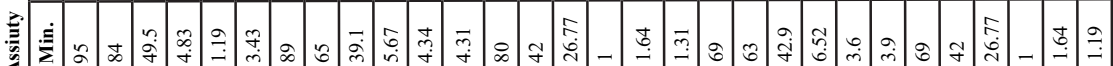

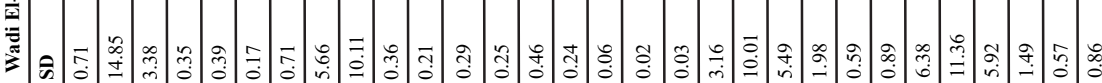

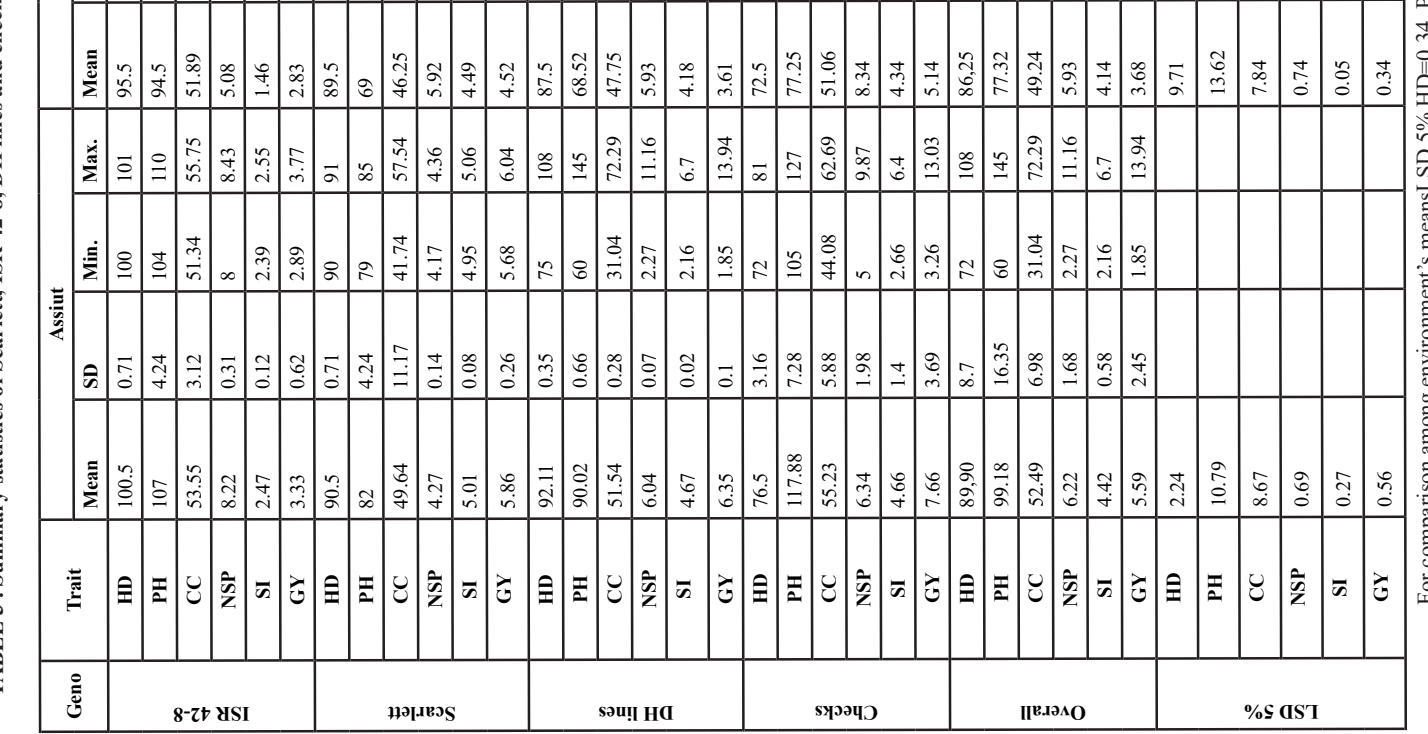

Egypt.J.Agron. Vol.39, No.1 (2017) 
was associated positively and significantly with each of chlorophyll content $\left(\mathrm{r}=0.153^{* *}\right)$, seed index $(\mathrm{r}=0.552 * *)$ and grain yield per plant $\left(\mathrm{r}=0.259^{* *}\right)$, while it was negative with number of spike per plant $\left(\mathrm{r}=-0.346^{* *}\right)$. There was positive correlation between chlorophyll content and seed index $(\mathrm{r}=0.152 * *)$, while negative correlations were found between $\mathrm{CC}$ and each of NSP and GYP across all locations. Highly positive correlation $(\mathrm{r}=0.321 * *)$ between number of spikes per plant and grain yield per plant was detected across environments. Also positive correlation was found between grain yield and seed index $\left(\mathrm{r}=0.064^{*}\right)$ across environments. von Korff et al. (2006) found negative correlation between yield and plant height, and positive correlation with number of spikes and days until heading .

\section{Identification of QTL in the S42 population}

Altogether, 56 putative QTLs as marker main effect and marker $\times$ environments interaction were detected for six studied traits across four environments namely; Assiut, Wadi El-Assiuty, Nubaria and Matrouh (Table 4 and Fig. 2). Among these loci, 25 (44.6\%) QTLs showed marker main effect, 27 (48.2\%) QTLs showed marker $\times$ environment interaction effects and $4(7.1 \%)$ QTLs showed both effects. 29 regions (51.7\%)

TABLE 4 . Correlation coefficients ( $r$ ) of the studied traitsacross environments.

\begin{tabular}{|l|l|l|l|l|l|}
\hline & PH & CC & NSP & SI & GYP \\
\hline HD & $-0.391 * *$ & $-0.172 * *$ & $0.384 * *$ & $-0.448^{* *}$ & $0.225 * *$ \\
\hline PH & & $0.153^{* *}$ & $-0.346^{* *}$ & $0.552^{* *}$ & $0.259^{* *}$ \\
\hline CC & & & $-0.071^{*}$ & $0.152^{* *}$ & -0.012 \\
\hline NSP & & & & $-0.39 * *$ & $0.321 * *$ \\
\hline SI & & & & & $0.064 *$ \\
\hline
\end{tabular}

* and **; significant at p-values of 0.05 and 0.01 , respectively.

exhibited desirable effects of the presence of the exotic alleles on the performance of the $\mathrm{DH}$ lines for the traits under investigation. All detected QTLs were covered the whole genome. Numerous studies on the same population revealed that detected QTL showed desirable effects resulted from the presence of exotic alleles of the homozygous Hsp genotype in population S42 ranged between 26 to $34.1 \%$ (Pillen et al., 2003 ; 2004 and Sayed, 2011).

\section{Days to $50 \%$ heading (HD)}

Time of flowering is a major trait of a crop adaptation to the environment, particularly when the growing season is prone to periods of drought and high temperatures. Developing early maturing varieties has been an effective strategy to mitigate yield losses of the crop exposed to an environmental stress and the end of the season (Kumar \& Abbo, 2001). Twelve putative QTLs for $\mathrm{HD}$ were mapped on chromosomes $1 \mathrm{H}$, $2 \mathrm{H}, 3 \mathrm{H}, 6 \mathrm{H}$ and $7 \mathrm{H}$ (Table 4 and Fig. 2). Eight loci exhibited significant marker main effects, while four regions showed QTL $\times$ environment interaction effects. According to the relative performance of the exotic allele $\left(\mathrm{Rp}_{[\text {[aa] }}\right)$, the alleles of nine QTLs were exhibited a desirable performance of reducing HD by $10 \%$. These QTLs showed negative additive effects. The strongest QTL was QHD.S42-3Hf showed main effect and explained $30.15 \%$ of the genetic variance. Furthermore, the QTL QHD.S42-1Hc exhibited increase in HD due to presence of the exotic allele that increased HD by $3.12 \%$, this QTL showed marker $\times$ environments. von Korff et al. (2006) identified ten QTLs for days until heading and covered the whole genome except chromosome $5 \mathrm{H}$, at five locations the exotic allele (Hsp) was associated with a reduced heading time of $7.9 \%$. The marker locus EBmac415 on $2 \mathrm{H}$ where the exotic allele decreased time to heading and coincided with the major flowering QTL on chromosome arm 2HS detected by Pillen et al. (2003), Li et al. (2004) and von Korff et al. (2006).

\section{Plant height (PH)}

Plant height is an important morphological trait, where shortening height of a plant can improve lodging resistance and may indirectly increase grain yield (Alam et al., 2007). Fifteen QTLs were detected for PH covered the whole genome except chromosome $7 \mathrm{H}$ (Table 4 and Fig. 2). Among these loci, seven QTLs showed significant marker main effects, six QTLs exhibited MEI effects and two loci showed both effects. Four chromosomal regions were responsible for shortening height of the plant by values ranged between -4.15 and $10 \%$ due to the presence of the exotic alleles. The strongest QTL was QPH.S42-2Hb and explained 14.85\% of the genetic variance. The other QTLs were 
$\wedge$
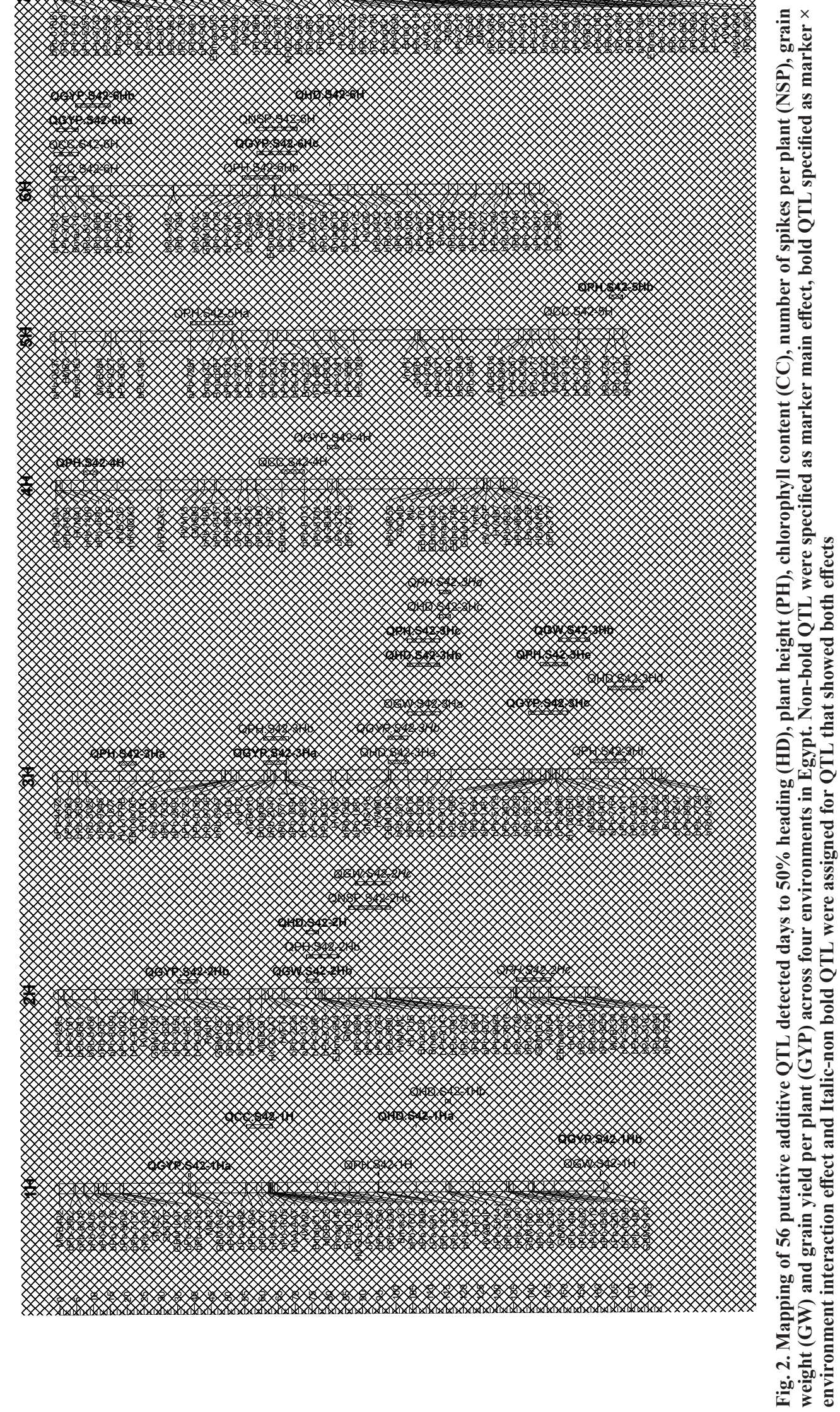

Egypt.J.Agron. Vol.39, No.1 (2017) 
responsible of increasing plant height by values ranged from 4.6 to $19.87 \%$ due to the presence of the exotic alleles. The strongest QTL was QPH.S42-3Hd posed $45.78 \%$ of the genetic variance. This locus showed marker main and marker $\times$ environment interaction effects. This finding is agreement with that obtained by Forster et al. (2004a) who detected QTL for plant height on $7 \mathrm{H}$ between 89 and $120 \mathrm{cM}$. We detected two marker (bpb_4092 on $2 \mathrm{H}$ and bpb_9110 on $3 \mathrm{H}$ ) that showed marker main and marker $\times$ environment interaction effects. The exotic alleles of these loci were responsible for increasing plant height. This reflects the stability of these markers across environments. previous studies detected QTL associated to $\mathrm{PH}$ on chromosome $7 \mathrm{H}$, where Baum et al. (2003) identified QTL with major effects on $2 \mathrm{H}, 3 \mathrm{H}$ and $7 \mathrm{H}$. In addition, Chloupek et al. (2006) and Gyenis et al. (2007) reported QTLs for PH on chromosomes $7 \mathrm{H}$. The detected QTL for $\mathrm{PH}$ in the current study are different from those reported by Sayed (2011) and Wang et al. (2010) in the same population. ISR 42-8 was taller than Scarlett under both treatments (Table 2), however the Hsp alleles led to shortening plant height in the DH lines. These results are consistent with the findings of Saal et al. (2010) and von Korff et al. (2010).

\section{Chlorophyll content (CC)}

Altogether four QTLs were associated significantly with $\mathrm{CC}$, three showed marker main effects and located on chromosomes $4 \mathrm{H}$, $5 \mathrm{H}$ and $6 \mathrm{H}$, on the other hand, a single locus showed MEI effect and mapped on 1H (Table 4 and Fig. 2). Relative performances of the exotic genotype ranged between $-4.07 \%$ and $10.55 \%$. The most desirable QTL was QCC. S42-5H and exhibited desirable performance of exotic alleles and revealed an increasing of CC by $9.83 \%$ and accounted $7.78 \%$ of the genetic variance. Xue et al. (2008) who detected four putative QTLs for chlorophyll content on chromosomes $2 \mathrm{H}, 3 \mathrm{H}$ and $6 \mathrm{H}$ obtained similar result. Since, individual QTL explained the variation from $6.3 \%$ to $20.2 \%$ of the total phenotypic variation. In addition, Guo et al. (2008) identified 5 QTLs on chromosomes 2 $\mathrm{H}$ and $4 \mathrm{H}$ associated with chlorophyll content in flag leaves at post-flowering stage under well-watered and drought conditions using a RIL population with 194 lines. Eshghi et al. (2013) who mapped five QTLs for chlorophyll content, with the $\mathrm{H}$, obtained similar results. , with the H. spontaneum alleles contributing to increased chlorophyll content at two of the five loci. The QTL with largest effect was located at 43-45 cM of chromosome $1 \mathrm{H}$ (linked to Bmag0105) and exotic alleles from wild barley increased this character by $33.8 \%$. The remaining four QTLs for chlorophyll content were detected on chromosomes $2 \mathrm{H}$, $5 \mathrm{H}$ and $6 \mathrm{H}$.

\section{Number of spikes per plant (NSP)}

Spikes number per plant is one of the most important grain yield-related traits in cereals. Six QTLs were detected for NPS and located on chromosomes $2 \mathrm{H}, 6 \mathrm{H}$ and $7 \mathrm{H}$ (Table 4 and Fig. 2). Four QTLs presented significant marker main effects, moreover two showed MEI effects. The relative performances of the exotic genotype ranged between $-10.71 \%$ and $11.54 \%$. Among these, four QTLs showed desirable performance of the exotic genotype alleles and revealed an increasing of NSP. The strongest QTL was QNSP.S42-2Hb and explained $8.56 \%$ of the genetic variance. This result indicates that the introgressions from wild barley may increase number of spikes/ plant in S42 population. Saal et al. (2010) have identified three QTLs as marker main effects associated with NSP and localized on chromosomes 1H (HVABAIP), 6H (GMS6) and $7 \mathrm{H}$ (BMAG7). In wheat, Ibrahim et al. (2010) detected five QTL associated to NSP, one of them increased NSP by $10.8 \%$ and $16.3 \%$ under well-watered and drought stress, respectively.

\section{0 - Grain weight (100-GW)}

Grain weight or seed index, is known as a representative quantitative trait. It is determined by synthesis and accumulation of starch in grain endosperm (You et al., 2006 and Mei et al., 2005). Results revealed that ISR 42-8 yielded less and had lower 100-grain weight than Scarlett under well-watered and drought conditions. Locations close to the six chromosomal regions (QTL) on $1 \mathrm{H}, 2 \mathrm{H}$ and $3 \mathrm{H}$ were probably influencing 100 -grain 
weight (Table 4 and Fig. 2). Two QTLs exhibited significant marker main effects, three loci exhibited significant MEI effects and one QTL showed both effects. Four QTLs revealed a desirable increase in 100-GW, and the exotic alleles explained maximum $7.11 \%$ of the genetic variance with favorably increased $100-\mathrm{GW}$ by $6.57 \%$. We identified one marker (Bmag125 on $2 \mathrm{H}$ ) that showed marker main and MEI effects. The exotic alleles of this locus was responsible for increasing this trait. Nine QTLs were responsible for 1000-GW and mapped on all chromosomes except $1 \mathrm{H}$ (von Korff et al., 2006).

\section{Grain yield/plant (GYP)}

Recently with the development of molecular approaches, QTL analysis was used to detect yield and its-related traits. QTLs associated with yield have been derived from wild species (Swamy \& Sarla , 2008). In our study, thirteen QTLs were detected for GYP and mapped in all choromosomes except $5 \mathrm{H}$ (Table 4 and Fig. 2). One QTL revealed significant marker main effect and showed undesirable effect by reducing GYP by $-8.63 \%$. Eleven QTLs revealed MEI effects and the relative performance of the exotic genotype ranged from -12.6 to $5.94 \%$ and accounted maximum $10.01 \%$ of the genetic variance. Only on QTL showed both effect with desirable increase in GYP due to the presence of the exotic alleles. This results are in harmony with those obtained by (Pillen et al., 2003 ; 2004; von Korff et al. 2006 ; 2010; Wang et al., 2010 and Sayed, 2011). We detected one marker (bpb_3278 on 3H) which revealed marker main and MEI effects. Therefore, this locus might be responsible for increasing this trait. We found that large and small segments of the wild parent ISR 42-8 were transmitted to the S42 population; therefore, we concluded that the wild parent ISR 42-8 might be responsible for diminishing GYP in S42 population.. However, the desirable identified QTL referred to possibility existance of Hsp regions may contribute to yield improvement, especially under drought conditions.

\section{Pleiotropic effects}

The collocation of QTL for different traits implies the likely presence of pleiotropic or closed linkage between the QTL control the traits (Tuberosa et al., 2002b). the present study revealed eight chromosomal regions covered the whole genome except $5 \mathrm{H}$. The marker locus $\operatorname{GMS} 3(81 \mathrm{cM})$ on $2 \mathrm{H}$ was controlling days to $50 \%$ heading and plant height and led to decrease both traits across environments. This locus may be useful for marker-assistant selection (MAS) in barley improvement for earliness and height shortening. The marker locus GBMS143 (162 $\mathrm{cM}$ ) on $1 \mathrm{H}$ was associated to 100 -grain weight and grain yield per plant, but increased grain weight and decreased yield. The marker locus EBmac775 (137 cM) on 7H was underlying the enhancement of number of spikes per plant and reducing days to $50 \%$ heading, this locus may be used in MAS for improving NSP and HD in multi-environments trials. Another two marker loci bPb_9681 (5.27 cM)) and bPb_8292 (27.06 $\mathrm{cM})$ on $2 \mathrm{H}$ were controlling NSP beside $\mathrm{PH}$ and $100-\mathrm{GW}$, respectively. The locus bPb_9110 (118.72 cM) was underlying $\mathrm{PH}$ and $\mathrm{HD}$, while the marker locus bPb_4209 (111.69 cM) on $3 \mathrm{H}$ was controlling $\mathrm{PH}, \mathrm{HD}$ and $100-\mathrm{GW}$. The marker locus Bmac316 (6 cM) on $6 \mathrm{H}$ was responsible of PH and GYP. Several genomic segments were found to include overlapped QTLs for different traits (Diab et al., 2004). Some QTLs showed pleiotropic effect, e.g. locus HVABAIP on chromosome $1 \mathrm{H}$ was associated with both 1000-GW and GY (Saal et al., 2010).

\section{Detection of epistasis}

Altogether 25 pairs of epistatic QTLs as additive $\times$ additive effects were detected for six studied traits in the S42 population across four environments in Egypt. Among them, five pairs exhibited QTL $\times$ QTL interaction, thirteen pairs exposed QTL by marker interaction and seven shown marker $\times$ marker interaction (Table 5). About 11 markers (44\%) of main-effect QTL detected for studied traits were involved in epistatic effects. This indicates that several loci involved in epistatic interactions may not have significant effects for these traits and may affect the trait expression by epistatic interactions with other loci. Likewise, Ma et al. (2007) stated that $37 \%$ of the main-effect QTLs were involved in the epistatic interactions in maize grain yield and its components. Zhang et al. (2008) found 25\% of main-effect QTLs for wheat plant height were involved in epistatic effects.

Days to $50 \%$ heading (HD)

Our results exposed seven pairs of epistatic QTLs were associated with days to 50\% heading and located on all chromosomes. Among these 
loci, five pairs of epistatic effects reduced the days to $50 \%$ heading. Since, the BC2DH lines carrying the Hsp/Hsp genotype at these loci were on maximum -1.89 day earlier than lines with the allelic combination $\mathrm{Hv} / \mathrm{Hv}$. The most desirable pair of epistatic QTLs for reducing heading date was (GMS3* bPb_3020) and located on chromosomes $2 \mathrm{H}(81 \mathrm{cM})$ and $7 \mathrm{H}(159.21 \mathrm{cM})$. The strongest epistatic pair (HVABAIP*bPb 9110) was mapped on $1 \mathrm{H}$ $(118 \mathrm{cM})$ and $3 \mathrm{H}(118.72 \mathrm{cM})$ and accounted for $40.67 \%$ of genetic variation (Table 5). Several studies on barley reported epistatic QTL for days to heading (Xu and Jia 2007; Sannemann 2013).

\section{Plant height (PH)}

Epistasis is an important genetic characteristic of quantitative traits such as plant height $(\mathrm{PH})$. Epistatic interaction analysis revealed six interaction effects for $\mathrm{PH}$ (Table 5). All pairs were responsible of increasing plant height of the DH lines across environments. The combination of Hsp/Hsp led to increase plant height by values ranged from 1.73 to $25.21 \mathrm{~cm}$. The strongest pair (GMS3* bPb_9110) was mapped on $2 \mathrm{H}(81 \mathrm{cM})$ and $3 \mathrm{H}$ $(118.72 \mathrm{cM})$ and posed of $55.79 \%$ of the genetic variance. Similar results were obtained by von Korff et al. (2010) have detected four epistatic interactions between exotic alleles $\mathrm{Hsp} / \mathrm{Hsp}$ transmitted from wild barley ( $H$. vulgare ssp. spontaneum C. Koch) which improved plant height significantly as compared to the combination Hv/Hv. Sannemann (2013) found two significant epistatic interactions for plant height.

\section{Chlorophyll content (CC)}

Results revealed only one pair of epistatic QTL (bPb_9746* bPb_1579) associated significantly with chlorophyll content and mapped on the same chromosome $3 \mathrm{H}(54.8$ and $115.5 \mathrm{cM}$ ). This locus accounted 4.88\% of the genetic variance and the DH lines that carrying the Hsp/Hsp combination were higher in chlorophyll content by 0.62 SPAD than lines carrying $\mathrm{Hv} / \mathrm{Hv}$ genotype. Zhang et al. (2009) detected nine pairs of QTLs with epistatic effects and/or epistasis $\times$ environment effects for chlorophyll content in wheat.

\section{Number of spikes per plant}

Epistatic analysis revealed four pairs of epistatic QTLs were associated significantly with number of spikes per plant and located on $2 \mathrm{H}, 4 \mathrm{H}$ and $5 \mathrm{H}$. At these loci, the $\mathrm{BC} 2 \mathrm{DH}$ lines carrying the Hsp/Hsp genotype were on maximum - 1.11 spike lower than lines with the allelic combination $\mathrm{Hv} / \mathrm{Hv}$.

\section{0-grain weight (100-GW)}

The epistasis analysis exposed five pairs of epistatic QTLs which were associated with SI and covered the whole genome except chromosome $4 \mathrm{H}$ (Table 5). The BC2DH lines carrying the Hsp/Hsp genotype at four loci were heavier weight by maximum $1.12 \mathrm{~g}$ than lines with the allelic combination $\mathrm{Hv} / \mathrm{Hv}$. The most desirable pair that showed positive effect was $\left(\mathrm{bPb} \_9681 * \mathrm{bPb} 4389\right)$ and mapped on $2 \mathrm{H}$ $(5.27 \mathrm{cM})$ and $7 \mathrm{H}(125.4 \mathrm{cM})$ and accounted $11.46 \%$ of the genetic variance. Sannemann (2013) found two significant epistatic effects for $1000-\mathrm{GW}$.

\section{Grain yield/plant (GYP)}

Two pairs of epistatic QTLs were associated significantly with GYP, and mapped on chromosomes $3 \mathrm{H}, 4 \mathrm{H}$ and $5 \mathrm{H}$ (Tables 5 and 6). Both pairs had positive effects of epistatsis on GYP, hence the BC2DH lines having the Hsp/Hsp genotype were higher GYP with value up to $1.47 \mathrm{~g}$ than lines with the allelic combination $\mathrm{Hv} / \mathrm{Hv}$. The strongest pair was $\left(\mathrm{bPb} \_3278 * \mathrm{bPb} 55265\right)$ and posed of $18.75 \%$ of the genetic variance. In contrast, von Korff et al. (2010) identified 12 interaction effects the allelic combination exotic by exotic caused a strong reduction in grain yield.

\section{CONCLUSION}

Some DH lines performed better than their parents and check varieties in each environment and across four environments as well. We concluded that some of DH lines were earlier than check cultivars. These DH lines can be selected directly for earliness. For GYP, some of the DH lines were yielded more than check cultivars and might be selected directly for high grain yield. Furthermore, the exotic alleles of these loci might be responsible for increasing their traits across environments. In addition, we detected eight markers loci possessed pleiotropic effect across locations. Our findings may be beneficial for barley breeding programs via MAS. 


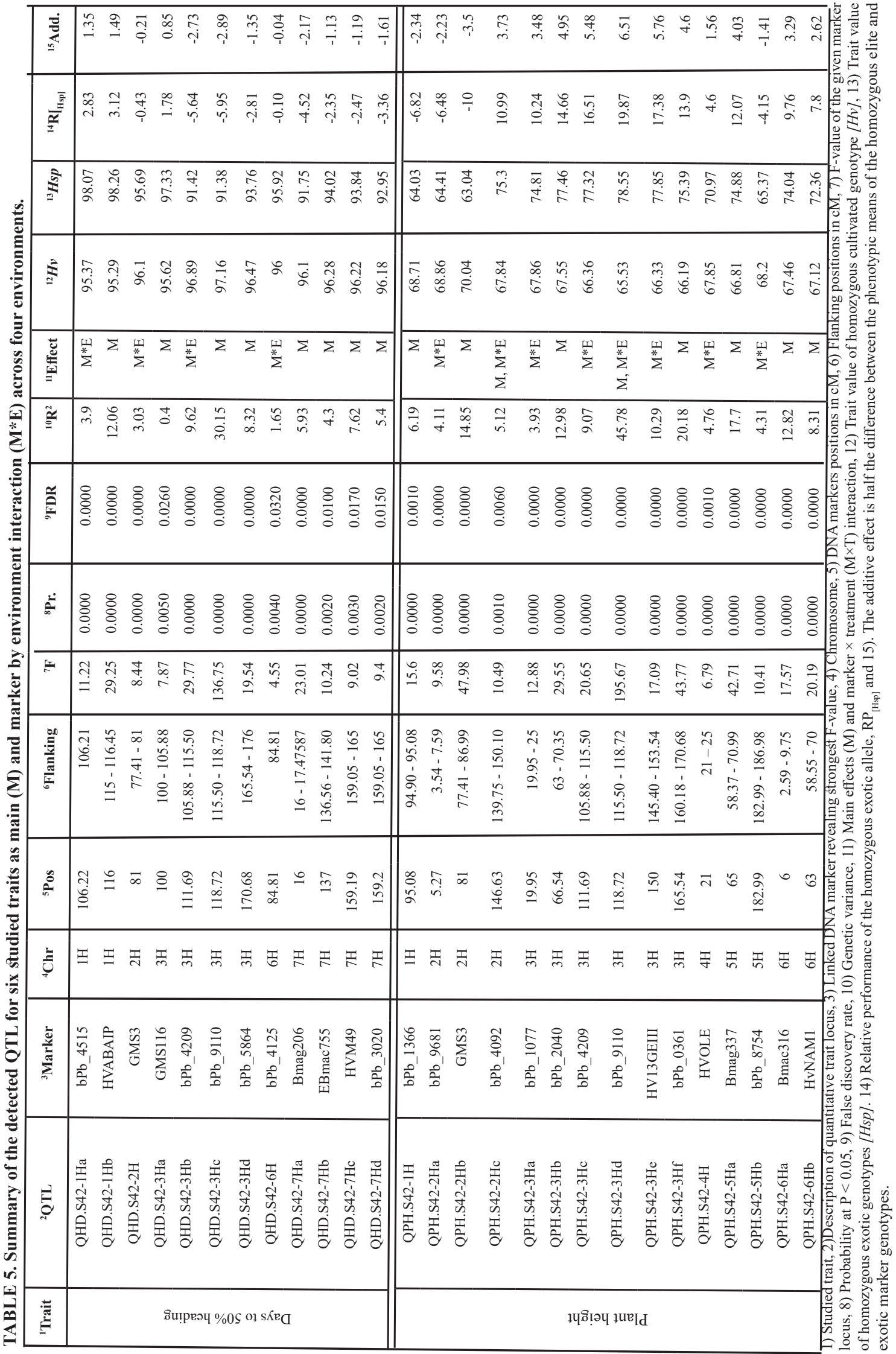

Egypt.J.Agron. Vol.39, No.1 (2017) 


\begin{tabular}{|c|c|c|c|c|c|}
\hline 离 & 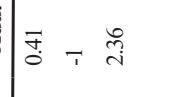 & 苔 & $\vec{m}$ कि. & 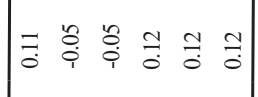 & 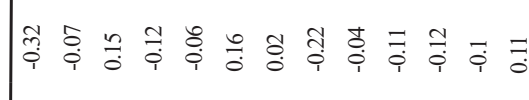 \\
\hline 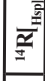 & 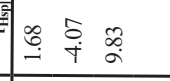 & $\stackrel{n}{\Leftrightarrow}$ & 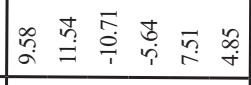 & 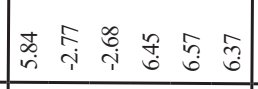 & 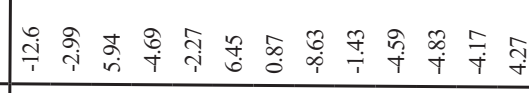 \\
\hline 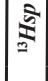 & 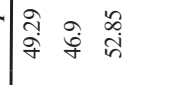 & ले & 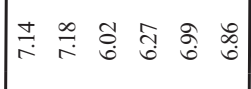 & 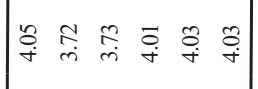 & 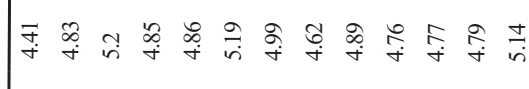 \\
\hline 空 & 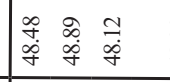 & 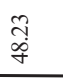 & 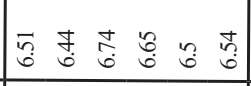 & 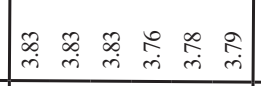 & 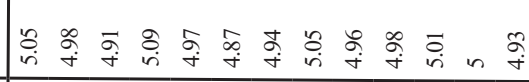 \\
\hline 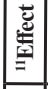 & $\frac{1}{2} \Sigma \Sigma$ & $\Sigma$ & 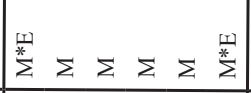 & 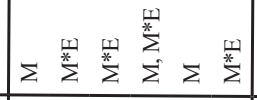 & 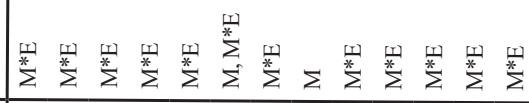 \\
\hline$\stackrel{\sim}{=}$ & 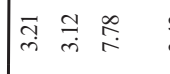 & $\stackrel{7}{m}$ & 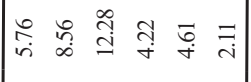 & 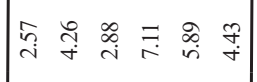 & 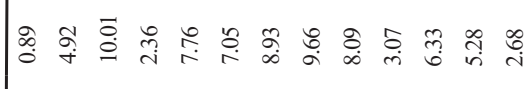 \\
\hline 盖 & 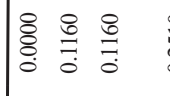 & 을 & 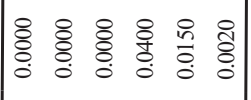 & $\left|\begin{array}{llllll}\circ & 0 & 0 & 0 \\
0 & 0 & 0 & 0 \\
0 & 0 & 0 & 0 & 0 \\
0 & 0 & 0 & 0 \\
0 & 0 & 0 \\
0\end{array}\right|$ & 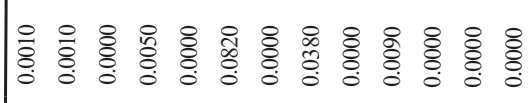 \\
\hline$\dot{+}$ & 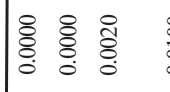 & $\stackrel{8}{\circ}$ & $\left|\begin{array}{lllll}0 & 8 & 0 & 0 & 0 \\
0 & 0 & 0 & 0 \\
0 & 0 & 0 & 0 & 0 \\
0 & 0 & 0 \\
0 & 0 & 0 \\
0\end{array}\right|$ & $\left|\begin{array}{llll}\circ & 0 & 0 & 0 \\
0 & 0 & 0 \\
0 & 0 & 0 & 0 \\
0 & 0 & 0 \\
0 & 0 \\
0\end{array}\right|$ & 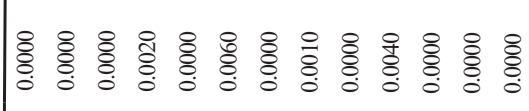 \\
\hline 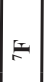 & 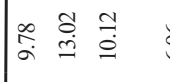 & : & 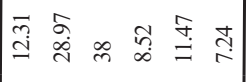 & 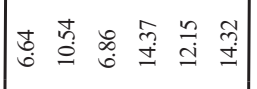 & 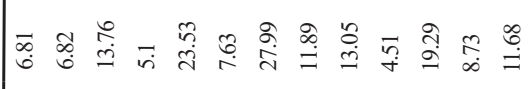 \\
\hline $\mid$ & 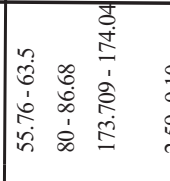 & $\begin{array}{l}\stackrel{9}{a} \\
\text { aे } \\
\text { ì }\end{array}$ & 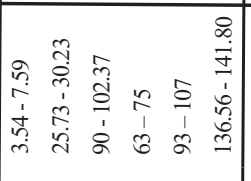 & 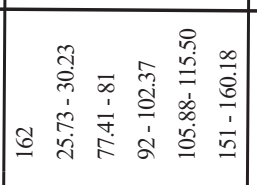 & 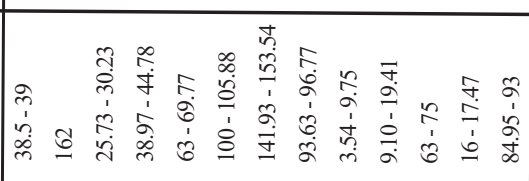 \\
\hline 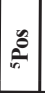 & 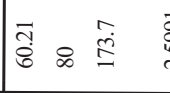 & बू & त) & 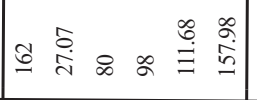 & 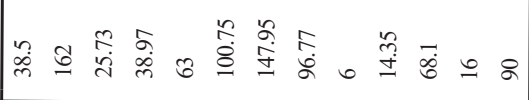 \\
\hline$\underline{\underline{z}}$ & $\Xi$ 专 & \& & 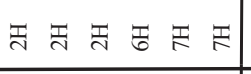 & 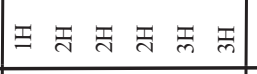 & 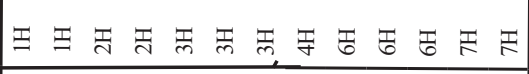 \\
\hline & 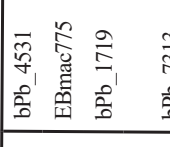 & 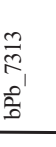 & 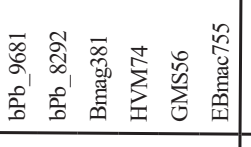 & 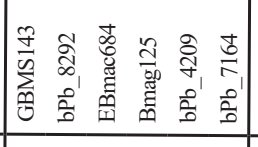 & 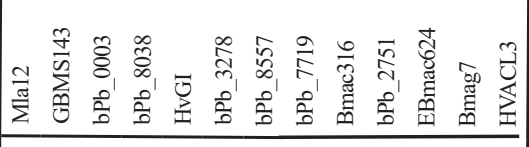 \\
\hline$\vec{z}$ & 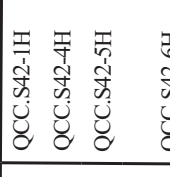 & 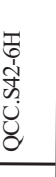 & 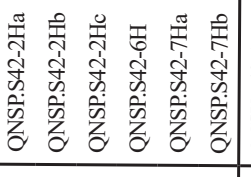 & 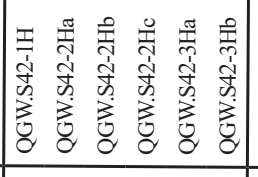 & 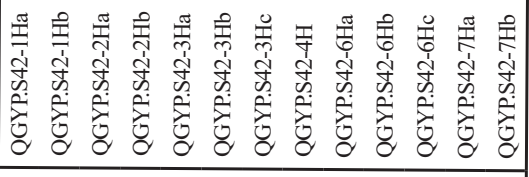 \\
\hline 竧 & 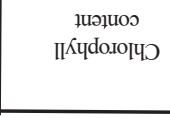 & & 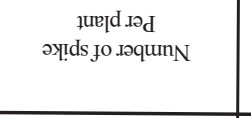 & 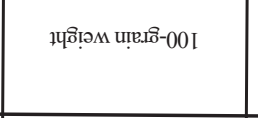 & 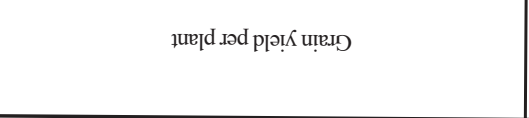 \\
\hline
\end{tabular}




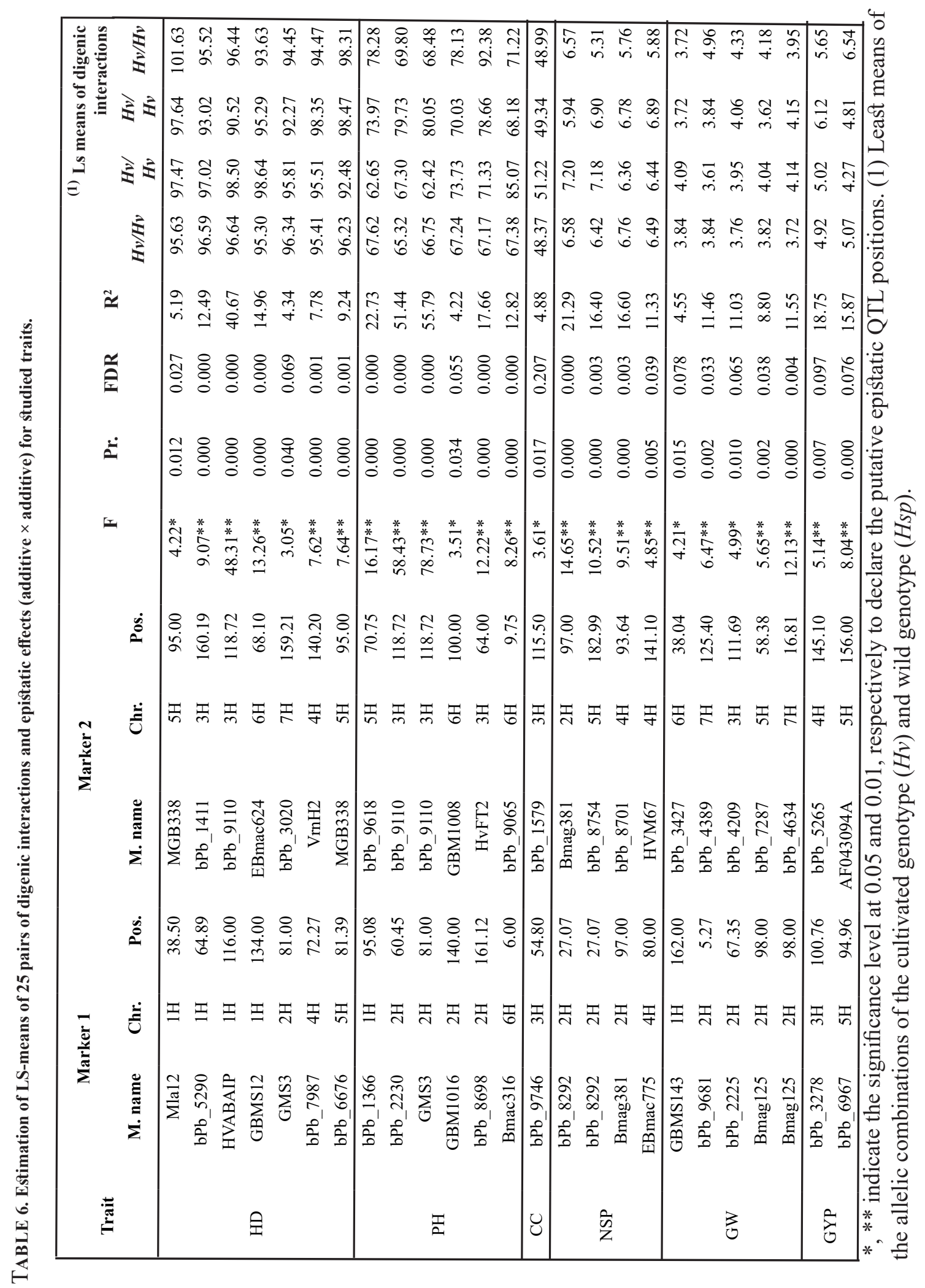

Egypt.J.Agron. Vol.39, No.1 (2017) 


\section{REFERENCES}

Adugna, A. (2007) Assessment of yield stability in sorghum. African Crop Science Journal,15(2), 83-92.

Alam, M.Z., Haider, S.A, and Paul, N.K. ( 2007) Yield and yield components of barley (Hordeum vulgare L). cultivars in Relation to Nitrogen Fertilizer. Journal of Applied Sciences Research, 3(10), 1022-1026.

Baum, M., Grando, S., Backes, G., Jahoor, A., Sabbagh, A. and Ceccarelli, S (2003) QTLs for agronomic traits in the Mediterranean environment identified in recombinant inbred lines of the cross 'Arta' x H spontaneum 41-1. Theoretical and Applied Genetics ,107,1215-1225.

Beyene, Y., Mugo, S., Mutinda, C., Tefera, T., Karaya, H., Ajanga, S,. Shuma, J. Tende, R. and Kega, V. (2011). Genotype by environment interactions and yield stability of stem borer resistant maize hybrids in Kenya. African Journal of Biotechnology, 10(23), 4752-4758.

Chloupek, O., Forster, B.P. and Thomas, W.T.B. (2006) The effect of semi dwarf genes on root system size in field-grown barley. Theoretical and Applied Genetics 112,779-786.

Cockerham, C.C. (1954) An extension of the concept of partitioning hereditary variance for analysis of covariances among relatives when epistasis is present. Genetics 39,859-882.

Cuesta-Marcos, A., Igartua, E., Ciudad, F., Codesal P., Russell, J., Molina-Cano, J., Moralejo, M., Szúcs, P., Gracia, M., Lasa, J.and Casas, A. (2008) Heading date QTL in a spring $\times$ winter barley cross evaluated in Mediterranean environments. Molecular Breeding 21,455-471.

Diab, A.A., Teulat-Merah, B., Dominique, T., Neslihan, Z., Ozturk, D.B. and Mark, E.S. (2004) Identification of drought- inducible genes and differentially expressed sequence tags in barley. Theoretical and Applied Genetics, 109,1417-1425.

El-Sayed, A.A., Noaman, M.M., Asaad, F.A., ElSherbini, A.M., El-Gamal, A.S., El-Bawab, A.M.O., El-Moselhy, M.A., Megahed, M.A., Abd El-Hameed, M. and Desouki, E.E. (1995) Giza 127 and Giza 128, new two-row barley cultivars. Egyptian Journal of Applied Science, 10,466-476.

El-Sayed, A.A., Abo-Elenin, R.A., El-Gamal, A.S., Megahed, M.A., El-Moselhy, M.A., El-Sherbini, A.M., El-Hag, A.A., El-Bawab, A.M.O., AbdelHameed, M., Amer, K.A., Mostafa, E.E., Grando, S., Ashmawy, H.A., Abaas, S.H.I., Shendy, M.Z., Said M.A .and Hawary, M.I. (2003) Giza 129 and Giza 130, two newly released hulless barley varieties for irrigated lands in Egypt. Proc, Third Plant Breeding Conference, Giza, Egypt, 26 April 2003. Egyptian Journal of Plant Breeding, 7,pp. 387-398.
Eshghi, R., Salayeva, S., Ebrahimpour, F., Rahimi, M., Baraty, M. and Ojaghi ,J. (2013) Advancedbackcross QTL analysis in hulless barley: I. Detection of exotic alleles for yield and yield components introgressed from Hordeum vulgare ssp. spontaneum. International Journal of Agriculture and Crop Sciences 5(2), $95-100$.

FAOSTAT. http://faostat.fao.org (accessed 31 October 2016).

Forster, B.P., Ellis, R.P., Moir, J., Talame, V., Sanguineti, M.C., Tuberosa, R., This, D., TeulatMerah, B., Ahmed, I., Mariy, S.A,. Bahri, H,. El Ouahabi, M., Zoumarou-Wallis, N., El-Fellah, M. snf Ben Salem, M.(2004) Genotype and phenotype associations with drought tolerance in barley tested in North Africa. Annals of Applied Biology, 144,157-168.

Guo, P., Baum, M., Varshney, R., Graner, A., Grando, S. and Ceccarelli, S. (2008) QTLs for chlorophyll and chlorophyll fluorescence parameters in barley under post-flowering drought. Euphytica, 163(2), 203-214.

Gyenis, L., Yun, S.J., Smith, K.P,. Steffenson, B.J., Bossolini,E., Sanguineti, M.C. and Muehlbauer, G.J.(2007) Genetic architecture of quantitative trait loci associated with morphological and agronomic trait differences in a wild by cultivated barley cross. Genome, 50(8),714-723.

Hayes, P.M,. Liu, B.H., Knapp, S.J., Chen, F., Jones,.B., Blake, T., Franckowiak, J., Rasmusson,.D., Srrells, M., Ullrich, S., Wesenberg, D., Kleinhofs, A. and Nilan, R. (1993) Quantitative trait locus effects and environmental interaction in a sample of North American barley germplasm. Theoretical and Applied Genetics, 87,392-401.

Ibrahim, S.E., Schubert,A., Pillen, K. and Léon, J. (2010) Quantitaive trait loci analysis for drought tolerance in an advanced backcross population of spring wheat. Sudan Journal of Agricultural Research $, \mathbf{1 5}, 118$.

Kandemir, N., Jones, B.J., Wesenberg, D.M., Ullrich, S.E. and Kleinhofs, A. (2000) Marker-assisted analysis of three grain yield QTL in barley (Hordeum vulgare L.) using near isogenic lines. Molecular Breeding 6,157-167.

Kang,M.S.(2004) Breeding: Genotype-byenvironment interaction. In: " Encyclopedia of Plant and Crop Science." R.M. Goodman (Ed.) MarcelDekker, New York. pp. 218-221.

Kumar, J. and Abbo, S. (2001) Genetics of flowering time in chickpea and its bearing on productivity in the semi-arid environments. Advances in Agronomy 72,107-138.

Lark, K.G., Chase, K., Adler, F.R., Mansur, L.M. and Orf, J.J. (1995) Inter-actions between quantitative trait loci in soybean in which trait variation at one 
locus is conditional upon a specific allele at another. Proceeding of the National Academy of Sciences USA 92,4656-4660.

Li, J.Z., Huang, X.Q., Heinrichs, F., Ganal, M.W. and Röder, M.S. (2006) Analysis of QTLs for yield components, agronomic traits, and disease resistance in an advanced backcross population of spring barley. Genome, 49(5), 454-466.

Li, J.Z., Huang, X.Q., Heinrichs, F., Ganal, M.W. and Röder, M.S. (2004) Analysis of QTLs for yield, yield components, and malting quality in a $\mathrm{BC} 3-\mathrm{DH}$ population of spring barley. Theoretical and Applied Genetics,110(2),356-363.

Li, Y.B., Fan, C.C., Xing, Y.Z., Jiang, Y.H., Luo, L.J., Sun, L., Shao, D., Xu, C., Li, X., Xiao, J., He, Y. and Zhang, Q. (2011) Natural variation in GS5 plays an important role in regulating grain size and yield in rice. Nature Genetics, 43, 1266-1269.

Li, Z., Pinson, S., Park, W., Paterson, A., Stansel, J. (1997) Epistasis for three grain yield components in rice (Oryza sativa L.).Genetics, 145, 453-465.

Ma, X.Q., Tang, J.H., Teng, W.T., Yan, J.B., Meng, Y.J., Li, J.S. (2007) Epistatic interaction is an important genetic basis of grain yield and its components in maize. Molecular Breeding. 20, 41-51.

Maughan, P.J., Saghai Maroof, M.A., Buss and G.R. (1996) Molecular-marker analysis of seed-weight: genomic locations, gene action, and evidence for orthologous evolution among three legume species. Theoretical and Applied Genetics, 93, 574-579.

Mei, H.W., Luo, L.J., Ying, C.S., Wang, Y.P., Yu,X.Q., Guo, L.B., Paterson, A.H. and Li, Z.K. (2005) Gene actions of QTL affecting several agronomic traits resolved in a recombinant inbred rice population and two backcross population. Theoretical and Applied Genetics, 110,649-659.

Mishra, B.N. and Shivakumar, B.G. (2000) Barley In: "Techniques and Management of Field Crop Production. Agrobios". Rothere, PS (Ed.), India.

Noaman, M.M. (2010) Barley development in Egypt In: Ceccarelli, S. and Grando, S. 2010. Proceedings of the $10^{\text {th }}$ International Barley Genetics Symposium, 5-10 April 2008, Alexandria, Egypt. pp.3-15.

Noaman, M.M., El-Sayed, A.A., Asaad, F.A., ElSherbini, A.M., El-Bawab, A.M.O., El-Moselhy, M.A. and Rizk, R.A. (1995a) Giza 125 and Giza 126 -two new barley cultivars for rain fed areas of Egypt. Egyptian Journal of Applied Science, 10, 418-432.

Noaman, M.M., El-Sayed, A.A. Asaad, F.A., ElSherbini, A.M., El-Bawab, A.M.O., El-Moselhy, M.A. and Rizk, R.A. (1995b) Registration of 'Giza 125'Barley. Crop Science, 35,1709-1709.

Noaman, M.M., El-Sayed, A.A., Asaad, F.A., El-

Egypt.J.Agron. Vol.39, No.1 (2017)
Sherbini, A.M., El-Bawab, A.M.O., El-Moselhy, M.A. and Rizk, R.A. (1995c) Registration of 'Giza 126' Barley. Crop Science, 35,1710-1710.

Noaman, M.M., Ahmed, I.A., El-Sayed, A.A., AboElenin, R.A., El-Gamal, A.S., El-Sherbini, A.M., Asaad, F.A., El-Hag, A.A., Moustafa, K.A., ElBawab, A.M.O., El-Moselhy, M.A., Megahed, M.A., Abd El-Hameed, M., Amer, K.A., Atia, A.A., Saad, M.F., Said, M.A., Shmawy, H.A., Rizk, R.A.and Mahfouz, H.A.T. (2007a) Registration of 'Giza 2000' drought-tolerant six-row barley for rainfed and new reclaimed areas in Egypt. Crop Science, 47, 441.

Noaman, M.M., Ahmed, I.A., El-Sayed, A.A., AboElenin, R.A., Ahmed, I.A., El-Gamal, A.S., ElSherbini, A.M., Abd El-Hameed, M.M., Megahed, M.A., El-Moselhy, M.A., El-Bawab, A.M.O., Amer, K.A., Saad, M.F., Ashmawy, H.A., Rizk, R.A. and Abd El-Tawab, Y.M. (2007b) Registration of 'Giza 132’ Barley. Crop Science, 47, 440 .

Pillen, K., Zacharias, A. and Léon, J. (2003) Advanced backcross QTL analysis in barley (Hordeum vulgare L). Theoretical and Applied Genetics, 107,340352.

Pillen, K., Zacharias, A . and Léon, J. (2004) Comparative AB-QTL analysis in barley using a single exotic donor of Hordeum vulgare ssp spontaneum. Theoretical and Applied Genetics ,108,1591-1601.

Saal, B., M., von Korff, M., Lèon, J. and Pillen, K. (2010) Advanced-backcross QTL analysis in spring barley: IV Localization of QTL 3 nitrogen interaction effects for yield-related traits. Euphytica, 177 (2), 223239.

Sannemann, W. (2013) Marker-trait-sensor association in a multi-parent advanced generation intercross (MAGIC). population in barley (Hordeum vulgare ssp. vulgare). PhD diss., Universitäts-und Landesbibliothek Bonn.

SAS Institute (2008) The SAS System for Windows, release 9.2. Cary NC: SAS Institute.

Sayed, M.A., Schumann, H., Pillen, K., Naz, A.A. and Léon J (2012) AB-QTL analysis reveals new alleles associated to proline accumulation and leaf wilting under drought stress conditions in barley (Hordeum vulgare L). BMC Genetics, 13,61

Sayed, M.A.A. (2011) QTL analysis for drought tolerance related to root and shoot traits in barley (Hordeum vulgare L.). PhD diss., Bonn, Univ., Diss., 2011).

Schmalenbach, I., Körber, N. and Pillen, K. (2008) Selecting a set of wild barley introgression lines and verification of QTL effects for resistance to powdery mildew and leaf rust. Theoretical and Applied Genetics, 117, 1093-1106. 
Singh, M., Ceccarell,i S. and Hamblin, J. (1993) Estimation of heritability from varietal trials data. Theoretical and Applied Genetics, 86, 437-441.

Swamy, M.B.P. and Sarla, N. (2008) Yield-enhancing quantitative trait loci (QTLs). from wild species. Biotechnology Advances, 26,106-120.

Tondelli, A., Francia, E., Visioni, A., Comadran, J., Mastrangelo, A.M., Akar, T., Al Yassin, A., Ceccarelli, S., Grando, Benbelkacem A., van Eeuwijk, F.A., Thomas, W.T.B, Stanca, A.M., Romagosa, I. andPecchioni, N. (2014) QTLs for barley yield adaptation to Mediterranean environments in the 'Nure' $\times$ 'Tremois' biparental population. Euphytica, 197(1),73-86.

Tuberosa, R., Sanguineti, M.C., Landi, P., Giuliani, M.M., Salvi,S. and Conti, S. (2002b) Identification of QTLs for root characteristics in maize grown in hydroponics and analysis of their overlap with QTLs for grain yield in the field at two water regimes. Plant Molecular Biology, 48,697-712.

von Korff, M., Wang, H., Léon, J. and Pillen, K. (2004) Development of candidate introgression lines using an exotic barley accession (H. vulgare ssp. spontaneum). as donor. Theoretical and Applied Genetics, 109(8), 1736-1745.

von Korff, M., Wang, H,. Léon, J. and Pillen, K. (2006) AB-QTL analysis in spring barley:II Detection of favourable exotic alleles for agronomic traits introgressed from wild barley ( $H$ vulgare ssp spontaneum). Theoretical and Applied Genetics, 112,1221-1231.

von Korff, M., Léon, J. and Pillen, K. (2010) Detection of epistatic interactions between exotic alleles introgressed from wild barley $(\mathrm{H}$. vulgare ssp. spontaneum). Theoretical and Applied Genetics 121(8): 1455-1464.

Voorrips, R.E. (2002) MapChart: software for the graphical representation of linkage maps and QTLs. The Journal of Heredity, 93, 77-78.

Wang, J., Sun, G., Ren, X., Li, C., Liu, L., Wang, Q., Du, B. and Sun, D. (2016) QTL underlying some agronomic traits in barley detected by SNP markers. BMC Genetics, 17,103-126.

Wang ,X., Pang, Y., Zhang, J., Zhang, Q., Tao, Y., Feng, B., Zheng, T., Xu, J. and Li, Z. (2014) Genetic background effects on QTL and QTL× environment interaction for yield and its component traits as revealed by reciprocal introgression lines in rice. The Crop Journal, 2(6), 345-357.

Wang, G., Schmalenbach, I., von Korff, M., Lèon, J., Kilian, B., Rode, J. and Pillen, K. (2010) Association of barley photoperiod and vernalization genes with QTLs for flowering time and agronomic traits in a $\mathrm{BC} 2 \mathrm{DH}$ population and a set of wild barley introgression lines. Theoretical and Applied Genetics 120,1559-1574.

Xu, S. and Jia, Z.(2007) Genome wide analysis of epistatic effects for quantitative traits in barley. Genetics, 175(4),1955-1963.

Xu, W., Rosenow, D.T. and Nguyen, H.T. (2000) Stay green trait in grain sorghum: Relationship between visual rating and leaf chlorophyll concentration. Plant Breeding, 119, 365-367.

Xue, D.W., Chen, M.C., Zhou, M.X., Chen,S., Mao, Y. and Zhang, G.P. (2008) QTL analysis of flag leaf in barley (Hordeum vulgare L.) for morphological traits and chlorophyll content. Journal of Zhejiang University Science B, 9(12), 938-943.

Yan, W., Hunt, L.A., Sheng, Q. and Szlavnics, Z. (2000) Cultivar evaluation and mega-environment investigation based on the GGE biplot. Crop Science, 40, 597-605.

Yan, W. and Kang, M.S. (2003) "GGE Biplot Analysis". CRC Press, New York.

You, A.Q., Lu, X.G., Jin, H.J., Ren, X., Liu, K., Yang, G.C., Yang, H.Y., Zhu, L.L. and He, G.C. (2006) Identification of quantitative trait loci across recombinant inbred lines and testcross populations for traits of agronomic importance in rice. Genetics, 172,1287-1300.

Yu, S.B., Li, J.X., Xu, C.G., Tan, Y.F., Gao, Y.J., Li, X.H., Zhang, Q. and Maroof, M.A.S. (1997) Importance of epistasis as the genetic basis of heterosis in an elite rice hybrid. Proceeding of the National Academy of Science, USA 94, pp. 9226-9231.

Zadok, J.C., Chang, T.T. and Konzak, F.C. (1974) A decimal code for growth stages of cereals. Weed Research, 14, 415-421

Zhang, K., Tian, J., Zhao, L. and Wang, S. (2008) Mapping QTLs with epistatic effects and QTL $\times$ environment interactions for plant height using a doubled haploid population in cultivated wheat. Journal of Genetics and Genomics, 35,119-127

Zhang, K., Fang, T., Liang, Y. and Tian, J. (2009) Genetic dissection of chlorophyll content at different growth stages in common wheat. Journal of Genetics 88(2), 183-189.

Zhu, H., Briceno, G., Dovel, R., Hayes, P.M., Liu, B.H., Liu, C.T., Ulrich, S.E. (1999) Molecular breeding for grain yield in barley: An evaluation of QTL effects in a spring barley cross. Theoretical and Applied Genetics, 98,772-779. 
تحليل المواقع الوراثية الكمية فى الثعير على مستوى البيئات فى مصر

$$
\begin{aligned}
& \text { محمد عبد العزيز عبد الحئي، أشرف نور الصادق"، بكرى أحمد بكرى** ، محمد بلرى على ،جينز ليون*** و }
\end{aligned}
$$

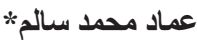

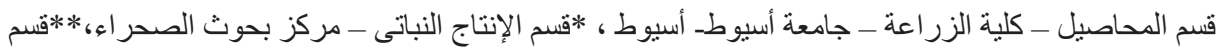

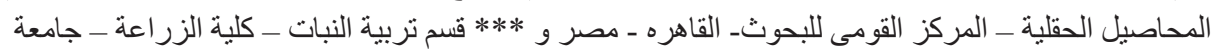

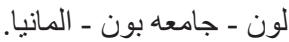

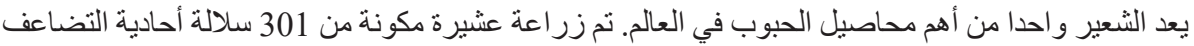

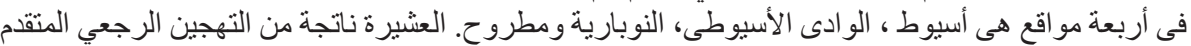

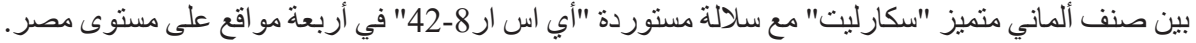

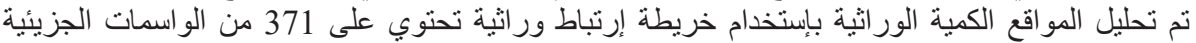

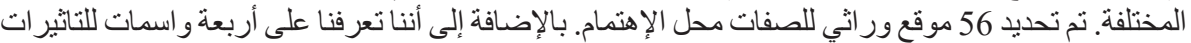

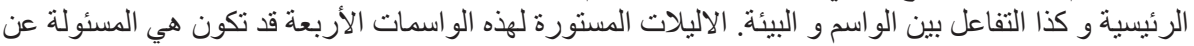

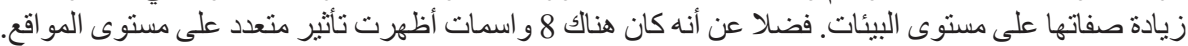

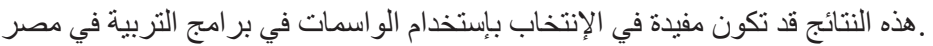

